\title{
Challenges Militating against the Effectiveness of Knowledge Management in Sustainable Land Use and Agricultural Production among Extension Workers in Sokoto State, Nigeria
}

\author{
Suleiman Yusuf Sheriff', Haruna Sule², Bello Zaki Abubakar ${ }^{3}$, \\ Muhammed Abubakar Maikasuwa', Faith Ikoghene Agbomakha ${ }^{4}$
}

\begin{abstract}
${ }^{1}$ Department of Agricultural Economics and Extension, Kebbi State University of Science and Technology, Aliero, Nigeria
${ }^{2}$ Department of Food and Strategic Reserve, Federal Ministry of Agriculture and Rural Development, Abuja, Nigeria

${ }^{3}$ Department of Agricultural Extension and Rural Development, Usmanu Danfodiyo University Sokoto, Sokoto, Nigeria

${ }^{4}$ Department of Vacational and Technical Studies, Federal College of Forestry Mechanization, Kaduna, Nigeria

Email: sy_sherif@yahoo.com, abubakarm188@gmail.com, anuruhsa@yahoo.com,bzgwandu@yahoo.ca,

faithagbomakha@yahoo.com
\end{abstract}

How to cite this paper: Sheriff, S.Y., Sule, H., Abubakar, B.Z., Maikasuwa, M.A. and Agbomakha, F.I. (2020) Challenges Militating against the Effectiveness of Knowledge Management in Sustainable Land Use and Agricultural Production among Extension Workers in Sokoto State, Nigeria. Agricultural Sciences, 11, 912-920.

https://doi.org/10.4236/as.2020.1110059

Received: August 10, 2020

Accepted: October 13, 2020

Published: October 16, 2020

Copyright $\odot 2020$ by author(s) and Scientific Research Publishing Inc. This work is licensed under the Creative Commons Attribution International License (CC BY 4.0).

http://creativecommons.org/licenses/by/4.0/

\begin{abstract}
The study assessed the Challenges Militating against the Effectiveness of Knowledge Management (KM) in Sustainable Land Use and Agricultural Production among Agricultural Extension Workers in Sokoto State, Nigeria. A sample size of 188 was drawn using well-structured questionnaires and was used for the study. Descriptive statistics and logit model were as tools of data analysis. The result of the study indicated that $53.7 \%$ of the extension Workers highlighted that lack of top Management support as major challenges for effectiveness of knowledge management among agricultural extension workers. The result of the logit model indicated that marital status, education level, experience, cosmopolitness and means of transportation had positive and significant relationship with effectiveness of Knowledge management. It was recommended therefore that Knowledge Management should be given top management support in all government establishments.
\end{abstract}

\section{Keywords}

Knowledge, Management, Sustainable, Land, Extension, Workers

\section{Introduction}

Knowledge management is concerned with ways of exchanging knowledge 
among those who can develop it and those who can use it. The lack of exchange of knowledge among and between farmers, and those who produce farm-relevant knowledge, has often been regarded as the key issue in pro-poor land use and agricultural development [1]. Against this backdrop, many agricultural extension and development programmes are run by both governments and international donor agencies. They focused on diffusing knowledge to farmers who, in turn, were expected to gain from applying this knowledge in their individual production practices [1].

On the other hand, Sustainable Land Use Management (SLUM) is a knowledge-based procedure that helps integrate land, water, biodiversity, and environmental management (including input and output externalities) to meet rising food and fiber demands while sustaining ecosystem services and livelihoods. Sustainable Land Use Management is necessary to meet the requirements of a growing population. Improper land management can lead to land degradation and a significant reduction in the productive and service (biodiversity niches, hydrology, and carbon sequestration) functions of watersheds and landscapes [2].

Effective extension professionals can be assets of agricultural extension services in Nigeria, particularly in Sokoto State. Diverse and dynamic agricultural systems, advancing science and technologies, changing socio demographics, increasing globalization and growing competition for resources demand agricultural extension professionals to be proficient in the technical aspects of their areas of expertise, as well as in the processes and delivery of the services (Cochran et al., 2012; Gibson and Brown, 2003; Maguire, 2012; Melak and Negatu, 2012; Rivera et al., 2009; Swanson and Rajalahti, 2010 cited in [3]).

Despite the continuous efforts of research, extension and development programmes to promote the generation and use of new knowledge in sustainable land use and agricultural production, agriculture still faces the challenges of knowledge identification, capturing, analysing, storing and sharing in Sokoto State. This creates a huge gap between extension services and rural farmers in solving the problem of sustainable land use and agricultural production [4]. World Bank report focuses on innovation which clearly implies that countries that neglect innovation will gradually fall behind. It is in this connection that $\mathrm{KM}$ remains an important vehicle for innovation as well as for enhancing efficiency of programmes and policies. It is against the background that this study was designed to assess the challenges mitigating against the effectiveness of KM in Sustainable Land use and Agricultural production in Sokoto State.

\section{Methodology}

\section{Sampling Procedures:}

Primary data was collected to answer the research questions as to achieve the desire objective of the study. The primary data include information on socio-economic characteristics of the agricultural extension workers and chal- 
lenges militating against the effectiveness of KM on sustainable land use management among extension workers. Other relevant data having direct and indirect bearing on the study was gathered from sampling of the Extension Workers using structured questionnaire and interview schedule. Sentiment deleted

\section{Sampling Technique and Sample Size:}

Purposive sampling was used to select ADP Extension Workers from Head Office and Zonal offices (i.e. Western and Northern Zones). Other Extension Workers included were sampled through preliminary surveys using purposive sampling. Purposive sampling technique (non-probabilistic) was adopted to ensure that only relevant respondents who are likely to provide quality, fruitful and meaningful data in the context of the study were included. A total of 200 responded were drawn from population of 398 Extension Workers form Sokoto Agricultural Development Project, between March, 2019 to September, 2019 as show in Table 1, with equal percentage from each department to form the sample frame as showed below and only 188 questionnaires was retrieved.

\section{Analytical Techniques:}

Descriptive and inferential statistics such as frequency distribution, percentage and logit regression model was used in data analysis.

\section{Logit Model}

In logit regression, the response variable $(Y)$ is a linear function of the coefficients $(B 0, B 1$, etc.) that correspond to the predictor variables $(X 1, X 2$, etc.). A typical model would look like:

$$
Y=B 0+B 1^{\star} X 1+B 2 * X 2+B 3 * X 3+\ldots B 1{ }^{*} X 10+E
$$

where $Y=$ Knowledge Management,

$B=$ bate (Coefficient)

$\varepsilon=$ Error term

$X=$ Variables $(X 1-X n)$

$X 1=\operatorname{Sex}$ (Is the gender of the Extension Worker of been a female or male)

$X 2=$ Marital Status (The state of being married or not married)

$X 3=$ Age (Age is the length of existence of Extension Workers in years)

$X 4=$ Education (Education is the process of facilitating learning, or the acquisition of knowledge, skills, values, beliefs, and habits of the Extension Workers and classified as post-Secondary education or other form of education)

$X 5=$ Experience (Is the number of years the Extension Workers put in service)

$X 6=$ Location (Location of duty of Extension workers either in the Head Office or Zonal Offices)

$X 7=$ Means Transportation (Means Transportation expresses the means of conveyance or travel from one place to another by Extension Workers is also classified as those who use Mobility (mobile) and those who trend on tracking (Non Mobile)).

Knowledge Management: 
Table 1. Sampling technique and size (Between the periods of March 2019 to September 2019).

\begin{tabular}{ccccccc}
\hline Departms. & HQ & NZ & WZ & Total & Sp/Size (\%) & No of Respondents \\
\hline Admin & 23 & 10 & 9 & 42 & 10.6 & 21 \\
Extension & 34 & 112 & 128 & 274 & 68.8 & 138 \\
Evaluation & 7 & 12 & 15 & 34 & 8.5 & 17 \\
Fadama & 6 & 4 & 6 & 16 & 4.0 & 8 \\
ICT & 15 & - & - & 15 & 3.8 & 7 \\
WIA & 5 & 5 & 7 & 17 & 4.3 & 9 \\
Total & 89 & 143 & 165 & 398 & $100 \%$ & 200 \\
\hline
\end{tabular}

Source: Field Survey 2018.

For a dichotomous response variable, a similar linear model was set up to predict individuals' category memberships if numerical values are used to represent the two categories. Arbitrary values of 1 and 0 are chosen for mathematical convenience. Using the first example, we assigned $Y=1$ if $\mathrm{KM}$ which is effective and $Y=0$ if $\mathrm{KM}$ is not effective or we assigned $X=1$ if respondent is male and $X=0$ if respondent is female.

\section{Definition and Measurement of Dependent Variable}

The dependent variable in the study is the Knowledge Management (KM). The independent variables which others invariably called explanatory variables are assumed to have influence on extension workers' in the use of Knowledge Management in sustainable land use and agricultural production. The variables (factors) in the study are; Sex, Marital Status, Age, Education, Experience, Location, and Means of Transportation The independent variables such as age and level of education were measured by using the measuring units of year and, year of schooling. Service experience was determined by the duration of experience of a respondent in agriculture extension service as shows in Table 2.

Table 2. List of Independent variables, unit of measurement and expected Sign.

\begin{tabular}{llll}
\hline Variable & Description & Measurement & Expected Sign \\
\hline Sex & Gender of extension worker & $1=$ Male, $0=$ female & + \\
Marital Status & Marital Status of ext. worker & $1=$ married, $2=$ single & + \\
Age & Age of the ext. worker & Years & $+/-$ \\
Education & Education Status & yeas & + \\
No. of Children & No. of children of ext. worker & Number \\
Experience & Experience of ext. worker & Years & $+/-$ \\
\hline
\end{tabular}

Source: Survey 2018.

Data Presentation, Analysis and Discussion

Challenges Militating against the Effectiveness of Knowledge Manage- 
ment in Sustainable Land Use Management and Agricultural Production among Extension Workers

Table 3 shows the challenges which were incurred through interviews and questionnaire with extension workers towards effectiveness of knowledge management in Sustainable Land Use Management and Agricultural Production among Extension Workers. The result indicated that lack of top Management support is the major challenges (53.7\%) for effectiveness of knowledge management among agricultural extension workers. Similarly, Alan, in presenting his findings on "Knowledge Management Failure Factors: Lessons from History", revealed that Knowledge Management requires strong guidance, decision-making, change implementation and so on. This exemplified the example set by management as well as their policies which, serve as a way to legitimise

Table 3. Challenges Militating against the effectiveness of Knowledge Management for Sustainable Land Use Management and Agricultural Production; $(\mathrm{n}=188)$.

\begin{tabular}{lll}
\hline Variable & Frequency & Percentage \\
\hline Lack of top management support & 101 & 53.7 \\
Lack of effective communication system & 38 & 20.2 \\
$\begin{array}{l}\text { Organisation culture (unavailability of IT and internet facilities in the } \\
\text { Organisation) }\end{array}$ & 20 & 10.6 \\
$\begin{array}{l}\text { Lack of separate budget for KM programs in the Organisation } \\
\text { Lack of training on KM for Extension Workers }\end{array}$ & 29 & 15.4 \\
$\begin{array}{l}\text { Resistant to change or unyielding behavior to change from traditional } \\
\text { extension system to KM driving extension }\end{array}$ & 14 & 22.3 \\
\begin{tabular}{l} 
Others \\
\hline
\end{tabular} & 8 & 4.5 \\
\hline
\end{tabular}

Source: Field Survey 2018.

$\mathrm{KM}$ and its importance in the organisation. For instance, the importance of top management backing for KM has been supported in other previous studies [5]. However, $20.3 \%$ of the Extension Workers attributed the challenges to lack of effective Communication system and $10.6 \%$ goes with Operation Culture (unavailability of internet and ICT facilities in the Organisation) as one of the major challenges to effectiveness of knowledge management in extension approach. This is in line with [6] NIAEM submission which illustrate that, Modern ICT, Internet and Web technology is needed to make these systems available regionally and globally. More so, accessing the Internet will bring a wealth of information to all agricultural stakeholders in rural and urban areas and will also help to overcome the digital divide. As most farmers have no hands-on-experience or access to digital networks and the leaders of national agricultural research and extension systems should be encouraged to consider the ICT opinion. The result further execrate that $15.4 \%$ of the Extension Workers explains that lack of separate budget for Knowledge Management programmes hindered the effectiveness 
of knowledge management in agricultural extension approach. In addition, Education and Training is very essential in the development process. Lack of education and training in basic skills contributes to the vicious cycle of under-development, low productivity and poor conditions of health and welfare of Extension Workers [7]. And Good number (22.3\%) of Extension Workers substantiates that lack of training and skills in Knowledge Management is one of the challenges for effectiveness of Knowledge Management in extension approach. Resistance to change or unyielding behaviour to change from traditional extension system to knowledge management driving extension system faces lot of challenges. Other challenges spotted by the extension workers which affect the effectiveness of Knowledge Management in agricultural extension approach are Inadequate Skill of Knowledge Managers and Workers, Lack of Relevance, Quality, and Usability, and Improper Implementation of Technology among others.

Ways of Improving Knowledge Management for Sustainable Land Use Management and Agricultural Production among the Extension Workers

For effectiveness and efficient extension services in the area of study, some Extension Workers were interviewed and the result is presented in Table 4. The result indicates that considerable number (45.7\%) of the Extension Workers are with the view that organizing different knowledge management programmes such as; seminars, workshops, conferences, training which spanned through FNT (forth night training), MTRM (monthly technical review meetings), FFBS (farmers field business school). The result depict that it will improve effectiveness of knowledge management in agricultural extension in sustainable land use management and agricultural production. This implies that Organisations require to emphasis on training and retraining of Extension Workers on Knowledge Management and ICT in order to achieve the desire objective. On this note, $18 \%$ of Extension Workers are with the opinion that providing regular information and awareness on Knowledge Management could improve extension activities. The result further reveals that among the Extension Workers, $13.8 \%$ belief that if Knowledge Management facilities and tool (internet and ICT facilities) is readily provided, it will aid effectiveness of extension services. This therefore portrays the work of Abubakar, that Internet is an emerging medium that is now assuming prominence among farmers in their quest to bridge the information generation and transmission gap. Internet has an edge over radio and television in terms of effecting behavioural change as it allows for instant interaction and feedback between the farmers and the extension workers [8]. And 2\% of the Extension Workers opine that provision of incentives and motivation to Extension Workers will facilitate application of Knowledge Management in order to effectively improve extension activities in Sustainable Land Use Management and Agricultural Production in the area of study. This is in accordance with Wu et al, assertion that Management must provide the resources necessary for Knowledge Management implementation [9]. Knowledge Management requires a great deal 
Table 4. Ways of improving knowledge management for sustainable land use management and agricultural production among the extension workers $(\mathrm{n}=188)$.

\begin{tabular}{ccc}
\hline Variable & Frequency & Percentage \\
\hline Organizing KM Programmes & 86 & 45.7 \\
Regular Information and Awareness & 43 & 22.9 \\
Management Support & 9 & 4.8 \\
Supervision & 13 & 6.9 \\
KM Facilities & 26 & 13.8 \\
Incentives and Motivation & 4 & 2.1 \\
Mobility & 17 & 9 \\
\hline
\end{tabular}

Source: Field Survey 2018.

of financial, human, and material resources; which includes the assignment of competent professionals and a sufficient budget. It also includes any resources needed for motivational support [5].

Relationship between Selected Characteristics of the Extension Workers and their Effectiveness of Knowledge Management in Sustainable Land Use Management and Agricultural Production:

Table 5 presented the logistic regression analysis computed in order to explore the coefficient relationship between the selected characteristics of the Agricultural Extension Worker and effectiveness of Knowledge Management in Sustainable Land Use Management and Agricultural Production among Extension Workers.

The correction of regression test indicted that education, years of experience, Cosmopoliteness, and means of transportation had positive and significant relationship with effectiveness of Knowledge Management in Sustainable Land Use Management and Agricultural Production whereas sex and age has positive but insignificant relationship and marital status had negative and significant relationship. Education is the process of facilitating learning, or the acquisition of knowledge, skills, values, beliefs, and habits. Formal education is commonly divided formally into such stages as preschool or kindergarten, primary school, secondary school and then college, university, or apprenticeship [10]. The more experience the Extension Worker would be the more informed about new technology and agricultural knowledge than their colleagues who had no much experience. This is in line with [3] submitted that those people who have been involved in either creation of new agricultural knowledge and innovations or communication of created knowledge for some years are informed than those who has less years in service. The Extension Workers that are cosmopolitan has a greater likelihood of his/her effectiveness in Knowledge Management in sustainable land use management and agricultural production. The result of also implied that an Extension Workers who are cosmopolite frequently come to contact with new people, new things and new ideas than their counterpart in the 
Table 5. Logit regression Model for Socioeconomic Characteristic factors influencing the Relationship of Extension Workers and their Effectiveness of KM in Sustainable Land Use Management and Agricultural Production (Log likelihood = 115.94299).

\begin{tabular}{|c|c|c|c|c|c|}
\hline $\begin{array}{l}\text { Dependent } \\
\text { Variable }\end{array}$ & $\begin{array}{l}\text { Impendent } \\
\text { Variable }\end{array}$ & $\begin{array}{l}\text { Co-efficient of }(r) \\
\text { correlation }\end{array}$ & \multicolumn{3}{|c|}{ Calculated value $\mathrm{P}>|\mathrm{z}|$} \\
\hline Effectiveness of & Marital Status & $-1.502^{\star *}$ & \multirow{6}{*}{$\begin{array}{l}10 \% \\
5-9.9\end{array}$} & \multirow{4}{*}{$\begin{array}{l}5 \% \\
1-4.9\end{array}$} & \multirow{4}{*}{$\begin{array}{l}1 \% \\
<1\end{array}$} \\
\hline Knowledge Management & Age & $0.205 \mathrm{NS}$ & & & \\
\hline in Sustainable Land Use & Education & $0.523^{* * *}$ & & & \\
\hline Management and & Experience & $0.325^{\star * *}$ & & & \\
\hline \multirow[t]{2}{*}{ Agricultural Production } & Location & $0.285^{\star * *}$ & & & \\
\hline & Means of Transp. & $0.295^{\star * *}$ & & & \\
\hline
\end{tabular}

${ }^{*}$ Significant at 0.05 level of probability, ${ }^{* *}$ Significant at 0.01 level of probability, ${ }^{* *}$ Significant at 0.00 level of probability, NS = Non significant.

rural areas. The findings collaborated with Muhammad et al., reported positive and significant relationship between perception of extension agent on sustainable agricultural practice in Rajshahi district of Bangladesh and Cosmopoliteness and stated that Cosmopoliteness thus can change the mental makeup of the people and make them more receptive for new ideas. Knowledge increases one's awareness, mental alertness, makes one familiar with facts, objects, concepts or practice [11]. The more convenience means of transportation for Extension Service delivery, the effectiveness of the Knowledge Management in Sustainable Land Use Management and Agricultural Production among Agricultural Extension Workers.

\section{Conclusion}

The important role of agricultural extension services in Sokoto State is highly imperative due to the nature of the people occupation. This study provides an insight on the use of Knowledge Management for effective agricultural extension delivery to the rural farming communities to solve the challenges that militate against Sustainable Land Use Management and Agricultural Production. However, the study has explored Knowledge Management in agricultural extension on Sustainable Land Use Management and Agricultural Production. Many empirical studies or works have been carried out in other places to assess Knowledge Management and have proved effectiveness in some areas while some areas need more improvement. More so, this study revealed that Knowledge Management helps to improves on the effectiveness of Agricultural Extension Service on Sustainable Land Use Management and Agricultural Production in the area study. The study also identified some of the challenges which hindered extension workers in the use of effective Knowledge Management in agricultural extension activities for Sustainable Land Use Management and Agricultural Production. These include: lack of top Management support, lack of effective Communication system, lack of separate budget for Knowledge Management programmes, 
lack of training and skills in Knowledge Management among Extension Workers, lack of relevance, quality, and usability as well as improper implementation of Technology.

\section{Conflicts of Interest}

The authors declare no conflicts of interest regarding the publication of this paper.

\section{References}

[1] Hartwich, F., Monge Pérez, M., Ampuero Ramos, L. and Soto, J.L. (2007) Knowledge Management for Agricultural Innovation: Lessons from Networking Efforts in the Bolivian Agricultural Technology System. Knowledge Management for Development Journal, 3, 21-37. http://www.km4dev.org/journal

[2] Orld Bank. (2006) Sustainable Land Management, Challenges, Opportunities, and Trade-offs Agriculture and Rural Development. The International Bank for Reconstruction and Development/The World Bank, 1818 H Street, NW, Washington DC 20433, Telephone 202-473-1000. http://www.worldbank.org/

[3] Mtega, W.P., Dulle, F.W., Malekani, A.W. and Chailla, A.M. (2014) A Wariness and Use of Web 2.0 Technologies Sharing of Agricultural Knowledge in Tanzania. Knowledge Management and E-Learning, 6, 188-202. https://doi.org/10.34105/j.kmel.2014.06.013

[4] World Bank. (2011) ICT in Agriculture: Connecting Smallholders Knowledge, Networks and Institutions, Report Number 64605. https://openknowledge.worldbank.org/handle/10986/12613

[5] Alan, F. (2014) A Synthesis of Knowledge Management Failure Factor, Knowledge Management Failure Factors: Lessons from History. Online Publication Retrieved 26th July 2018. http://www.knowledge-management-tools.net/

[6] NIAEM National Institute of Agricultural Extension Management (Undated) An Organisation of Ministry of Agriculture, Government of India Rajendranagar, Hyderabad. Online Publication, Retrieved: 31 May, 2017. http://www.manage.gov.in/

[7] Odejide, A. (1998) Income Generation Programmes for Women in Development. An Appraisal, Workshop on Women in Economic Development NCEMA, 7-11 September, 4-10.

[8] Abubakar, M. (2017) Socio Economic and Psychological Factors Influencing Adaption of Improved Gum Arabic Production Technologies by Farmers in Gombe State, Nigeria. PhD Theses, Department of Agricultural Extension Rural Development, Usmanu Danfodioyo University, Sokoto Sokoto State, Nigeria.

[9] Wu J., Du, H., Li, X. and Li, P. (2010) Creating and Delivering a Successful Knowledge Management Strategy. In M. Russ (Ed.), Knowledge Management Strategies for Business Development. Hershey.

https://doi.org/10.4018/978-1-60566-348-7.ch012

[10] Google Dictionary (2019) Education Meaning. Retrieved $14^{\text {th }}$ January 2019.

https://www.academia.edu/

[11] Islam, M.R., Rahman, M.M.U., Pervez, A.K.M. and Kamaly, M.H.K. (2013) Perception of Extension Agents about Sustainable Agricultural, Department of Agronomy and Agricultural Extension, University of Rajshahi, Rajshahi, Bangladesh. Upazilla Agriculture Office, Tanore, Rajshahi, Bangladesh. 